\title{
Vereinigung der Schweizer schriftstellernden Ärzte und Ärztinnen
}

Die Vereinigung der Schweizer schriftstellernden Ärzte und Ärztinnen (ASEM Association Suisse des Ecrivains Médecins) wurde 1956 in Basel gegründet (ihr erster Präsident war ein Tessiner) und hatte anfänglich intensiven Kontakt zu den französischen und deutschen Kollegen. Bald entstand ein europäischer Dachverband FISEM (Fédération internationale ...), der mit der Teilnahme von Brasilien und Kanada in UMEM (Union Mondiale des Ecrivains Médecins) umbenannt wurde. Der polyglotte Basler René Kaech war ihr Präsident in den ersten Jahren. Seit 1997 ist wieder ein Schweizer Präsident.

In der ASEM vereinen sich Kolleginnen und Kollegen aus allen Schweizer Sprachgebieten, die sich aktiv belletristisch betätigen und möglichst auch publizieren. Zum Teil sind sie zusätzlich Mitglieder anderer Schriftstellervereinigungen. Wir treffen uns locker zu Vortrags- und Diskussionsarbeitstagungen und stellen uns seit einigen Jahren in öffentlichen Lesungen dem Publikum (Schinznach, Brienz, Mailand, Zürich, Biel, Interlaken, nächstens Bern); eine wichtige Bereicherung.

Mitglieder der nationalen Ärzteschriftstellerverbände sind selbstredend an die UMEM-Konferenzen zum Vortragen aus ihren Werken eingeladen, nun auch in Ländern, die unsere Offenheit nach Osten aufzeigen (Bulgarien, Griechenland, Rumänien, Polen, 2001 wieder Griechenland), dies nach Jahren der erzwungenen Westeuropalastigkeit mit Belgien, Frankreich, Deutschland, Italien, Spanien, Portugal und mit den Kongressen in der Schweiz, 1983 in Ascona und 1999 in Studen/Biel. Sprachliche Schwierigkeiten werden durch ein Skriptum mit dem Originaltext und mindestens einer Übersetzung gemildert.

So haben wir im Oktober des letzten Jahres vier spannende Tage in Lodz/Polen erlebt. Wir haben den polnischen Kollegen vorgeschlagen, ihre Mitteilungen am Kongress in der Schweizerischen Ärztezeitung zu veröffentlichen, um ihr Gedankengut in der Schweiz weiterzugeben. Die Idee ist, nach jedem UMEM-Kongress via Distillerieseiten einige schriftstellerisch aktive Kolleg(inn)en aus dem jeweiligen Gastland vorzustellen.

\section{Vorstand ASEM}

Eduard Kloter, Präsident ASEM und UMEM, Kreuzbühlweg 18, 6045 Meggen, Tel. 0413773120

Sergio Marengo, Vicepresidente ASEM, 6644 Orselina, Tel. 0917439059

Françoise Verrey Bass, Viceprésidente ASEM et Trésorière, Quai du Bas 35, 2502 Bienne, Tél. 0323235640

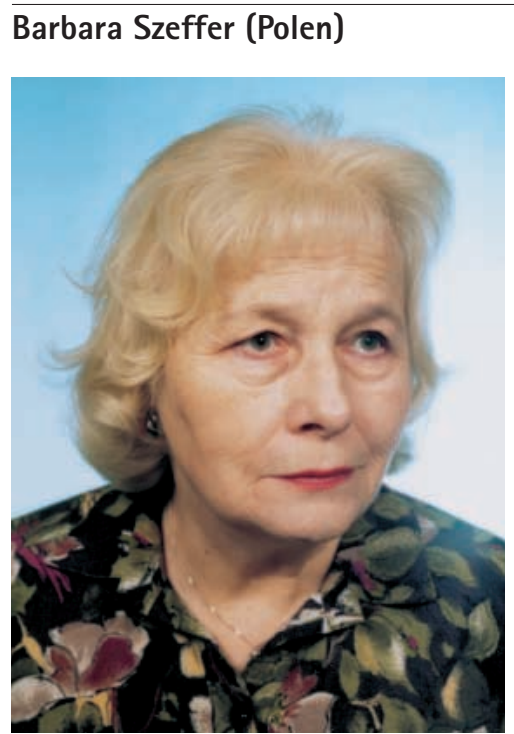

Barbara Szeffer-Marcinkowska, geb. ca. 1930 in Warschau, ist Kieferchirurgin und spezialisiert in Orthopädie und Traumatologie. Sie schrieb bereits im Gymnasium und erhielt Literaturpreise. Sie hat sehr viel veröffentlicht, vor allem Gedichtbände. Sie hat auch in jedem Almanach der UPPL (polnische ASEM) seit 1978 publiziert. Sie ist seit zehn Jahren UPPLPräsidentin.

\section{Das weisse Gedicht}

Ich will für dich dichten ein weisses Gedicht aus Porzellanmüschelchen,

aus Schaumköpfen, ausgespült von den Wellen, aus verlorenen Seeschwalbenfederchen, aus Wolken, Nebeln, Andeutungen, Vermutungen, Ängsten und Zögern, Erwarten, Bedauern, Verzagtheit und vergessenen Freuden.

Ich will für mich dichten ein weisses Gedicht aus den kleinen Schneeflocken hier, aus dem Tüll der Gardinen am Fenster, der Kälte im einsamen Bett, der geweisselten Decke zu Häupten, aus weisser Liebesglut, Empfindungen weiss gewordener Asche und dem Schleier in meinem Auge.

Ich will für uns dichten ein weisses Gedicht ohne Ende, ohne Anfang auf dem milchigen Weg durch die Wüste, eins das ich eingraviere mit Kreide und Salz, tünche mit gelöschtem Kalk des allmächtigen Universums und mit dem Weiss weggeworfener Knochen ... Ich dichte uns ein heimtückisches Gedicht. 


\section{Marek Pawlikowski (Polen)}

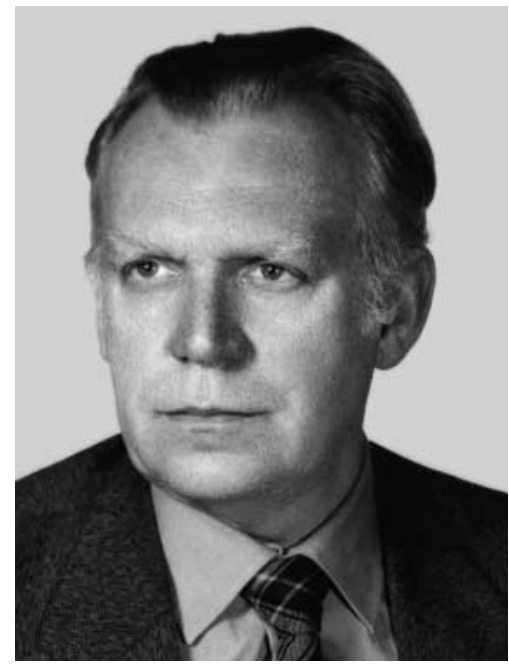

Marek Pawlikowski, geb. 1933 in Poznan. Seit 1975 ist er Professor für Endokrinologie an der Medizinischen Fakultät in Lodz, deren Rektor er auch einige Jahre war. 1992/93 war er Gastprofessor an der Universität Claude-Bernard in Lyon (F). Er ist in seinem Fach international bekannt dank seiner wissenschaftlichen Veröffentlichungen. Er schreibt seit 1994, vorwiegend Gedichte. Er hat einen Gedichtband publiziert. Seit 1998 ist er Vizepräsident der UPPL.

Der jüdische Friedhof

Zwischen wilden Sträuchern, wuchernd in der Böschung, stehen die steinernen Mazewot wie eine Gruppe Leute, bewegungslos, erstarrt, auf dem Weg ins ferne Jerusalem, stolpernd,

zu Füssen fallend, irgend etwas flüsternd in unverständlicher Sprache Euch wurde die Gnade erwiesen die Zeit nicht abwarten zu müssen bis zum Holocaust Eure jüngeren Brüder, eure Nachkommenschaft ist zu namenloser Asche geworden Erlaubt, dass ich für sie und Euch ein Gebet hier spreche zu unserm gemeinsamen Gott
Sankt Antonius

Hilf uns, uns wiederzufinden, verloren im Chaos der Galaxien, zersetzt in subzelluläre Strukturen, Atome und Moleküle, vergeblich den Sinn dessen suchend, was uns umgibt Hilf uns wiederzufinden den rechten Weg, den wir kennen wie die Strassen der Heimatstadt, Verlorenes aufzufinden wie Glaube, Hoffnung und Liebe

Der Wimpel von Don Quijote Das Geschlecht von Sancho Pansa lümmelt sich hin und macht sich breit kreuz und quer durch Europa in Palästen aus Glas und Aluminium Wir schauen amüsiert verblüfft beschämt auf die verschossene Fahne gehoben auf seine Lanze durch ein Skelett, das einstmals Don Quijote de la Mancha genannt ward und wir entziffern mühsam ein Wort gut sichtbar darauf das es nicht mehr gibt in unseren Sprachen EHRE
Abend
Der Septemberabend hat den bittern Geschmack von Rotwein
Die leichte Brise
kündet noch nicht von
herbstlicher Kühle
Strohfeuer
verglimmen zu Asche
und Rauchschwaden
hängen im Garten
Der Schatten wird immer dichter,
doch der Tag ist noch nicht zu Ende 